\title{
Impactos do controle do preço da gasolina sobre o etanol biocombustível no Brasil
}

\author{
Cinthia Cabral da Costa \\ Pesquisadora - Embrapa Instrumentação \\ Endereço: Rua XV de Novembro, 1452 - São Carlos/SP \\ CEP: 13560-970 - E-mail: cinthia.cabral.da.costa@gmail.com
}

\author{
Heloisa Lee Burnquist \\ Professora - Escola Superior de Agricultura Luiz de Queiroz (ESALO/USP) \\ Endereço: Av. Pádua Dias, 11 - Piracicaba/SP \\ CEP: 13400-970 - E-mail: hlburnqu@usp.br
}

Recebido: 24/04/2014. Aceite 03/06/2016.

\section{Resumo}

Este trabalho estimou os efeitos do controle de preço da gasolina A sobre os preços do etanol hidratado e da gasolina C no Brasil. Para isto, foram estimados os preços que teriam prevalecido sem a intervenção. Os resultados mostram que a intervenção do governo no preço da gasolina beneficiou a produção do etanol hidratado por manter seu preço 9\% acima do que poderia ter ocorrido, em média, no período 2006 a 2010. No período 2011 a 2014, a intervenção governamental reduziu o preço da gasolina, afetando negativamente o preço do etanol hidratado ( $7 \%$ abaixo do preço estimado) e sua produção, além da saúde financeira da empresa estatal ofertante de gasolina $A$. Em 2015, o governo restringiu a internalização de reduções no preço internacional da gasolina, mantendo o preço doméstico 7\% acima do esperado, e prejudicando a competitividade de setores da economia brasileira demandantes de combustível fóssil como insumo de produção.

\section{Palavras-Chave}

Preços. Intervenção governamental. Biocombustível. Gasolina. Etanol. Brasil.

\begin{abstract}
This work estimated the effect of price control of gasoline A on the hydrated ethanol and gasoline $C$ in Brazilian fuel markets. For that, the prices that would prevail without intervention were evaluated. The results show that the Brazilian government intervention in the gasoline price stimulated the production of hydrated ethanol by keeping its price $9 \%$ higher than estimated, on average, along the period of 2006 to 2010 . Through the 2011 to 2014 period, the government intervention reduced gasoline price, what had a negative effect on the hydrous ethanol price (7\% lower than estimated) and its production, as well as the financial health of the state firm that supplies gasoline A. In 2015, the government restricted the transmission of reductions in the international price of gasoline to the domestic market, keeping the domestic price $7 \%$ higher than expected, and harming the competitiveness of the Brazilian economic sectors for which fossil fuel is a relevant item in the production cost.
\end{abstract}

Keywords

Prices. Government intervention. Biofuel. Gasoline. Ethanol. Brazil.

\section{JEL Classification}

Q41. Q42. Q43. Q48. 


\section{Introdução}

Na primeira década dos anos 2000, a política brasileira de combustíveis reativou, de forma estratégica, a produção e uso de biocombustíveis no cenário nacional, atribuindo a importância devida ao emprego de tecnologias modernas para atender ao objetivo de redução das emissões de CO2. Pelo lado do consumo, a introdução do carro flexfuel em 2003, provocou também um importante avanço da demanda do biocombustível no mercado doméstico. Já na segunda década dos anos 2000, no entanto, o governo brasileiro introduziu mudanças nas políticas de combustível por meio de uma maior intervenção no preço da gasolina $\mathrm{A}^{l}$ e com consequências distintas neste mercado.

Este estudo procurou identificar os impactos deste controle de preços. Para isto, a pressuposição básica adotada para analisar o efeito das distorções nos preços considera que a magnitude da intervenção governamental nos preços da gasolina A pode ser representada como a diferença entre o preço praticado de gasolina $\mathrm{A}$ e o preço do mercado internacional (isto pressupõe que o país é pequeno em termos econômicos neste mercado). A Figura 1 apresenta uma comparação entre a evolução relativa dos preços de importação da gasolina no Brasil, que acompanha o comportamento do preço do petróleo, com o preço praticado domesticamente. O preço praticado no país é apresentado nesta figura sem os impostos, de maneira que seja diretamente comparável ao preço de importação. Também é apresentado este preço doméstico acrescido de um imposto federal: a Contribuição de Intervenção no Domínio Econômico (Cide), uma vez que a oscilação dos valores praticados para a Cide foi, juntamente com o controle de preço da gasolina $\mathrm{A}$, as duas políticas adotadas para o controle do preço da gasolina para o consumidor final, também chamada de gasolina $\mathrm{C}$.

Verifica-se na Figura 1 que, enquanto o preço de importação da gasolina no país sofreu grandes oscilações, o preço nominal da gasolina A no mercado doméstico apresentou uma variação muito inferior àquele no período analisado. A diferença observada entre estes preços confirma o tratamento diferenciado da gasolina no país. A Figura

\footnotetext{
${ }^{1}$ Tipos de combustíveis de veículos leves no mercado brasileiro compreendem a Gasolina C, que corresponde à gasolina vendida em todo o país: constitui-se em uma mistura da $75 \%$ de gasolina A com 25\% de etanol anidro pelas distribuidoras é chamada de gasolina C; etanol hidratado utilizado diretamente como combustível.
} 
2 complementa esta análise, mostrando como o controle no preço do combustível fóssil afetou a relação do preço deste combustível com o seu substituto, o etanol hidratado.

Esta intervenção teve três fases distintas, até os dias atuais. Na primeira, cujo pico foi nos anos de 2008 até 2010, o preço doméstico da gasolina sem impostos, que deveria seguir o preço de importação deste produto, não acompanhou a tendência de queda daquele. Assim, o incremento do preço da gasolina era repassado para o consumidor final. Como pode ser verificado na Figura 2, neste período o preço do biocombustível apresentou um maior distanciamento do preço do concorrente fóssil, de forma que a competitividade do etanol hidratado assegurava a expansão do mercado para o biocombustível.

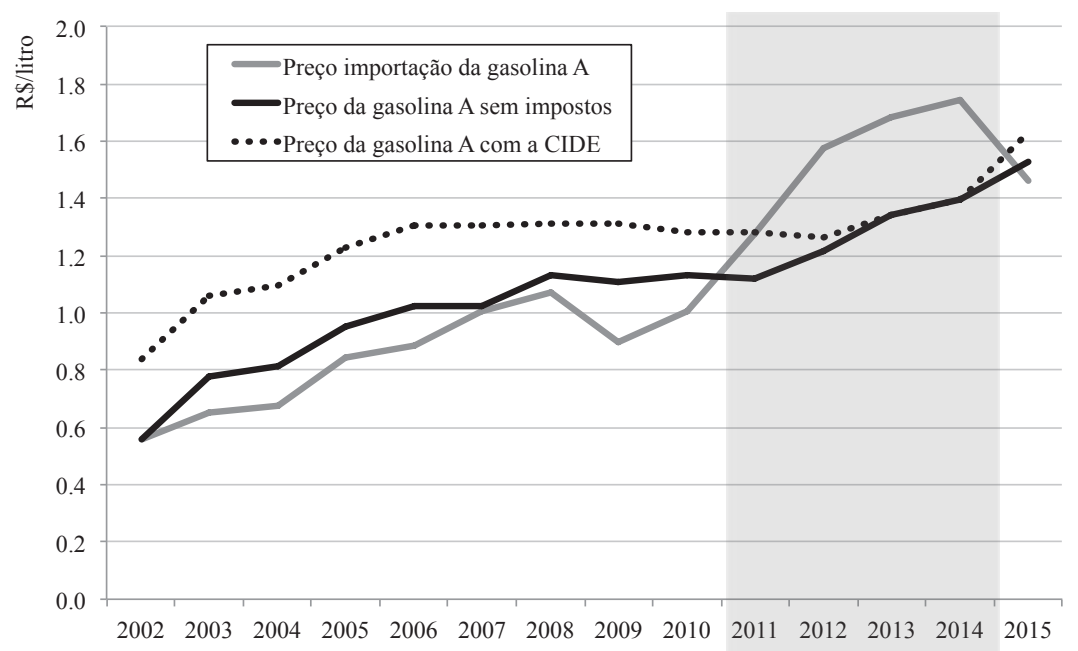

Figura 1 - Evolução dos preços da gasolina A no mercado internacional e no mercado doméstico, sem impostos e com Contribuição de Intervenção no Domínio Econômico (Cide). Período: 2002 a 2015

Fontes: Brasil (2016c); UNCTSD (2014); ANP (2016); Brasil (2016a).

Já a partir de 2011, o redirecionamento da política governamental torna-se evidente, sendo que o preço doméstico da gasolina passa a ser subsidiado pelo governo federal. Isto é verificado na Figura 1 pelo preço de importação da gasolina A no país em níveis superiores ao praticado no país. Além de manter o preço da gasolina A abaixo do seu preço referencial de importação, o governo também foi reduzin- 
do o valor da Cide até sua eliminação em 2012, mantendo-se zerada também nos anos de 2013 e 2014, como tentativa de manter baixo o preço da gasolina para o consumidor final. ${ }^{2}$ Na Figura 2, observase, neste período, o estreitamento entre os preços dos combustíveis fóssil e do derivado da cana-de-açúcar, dificultando, neste novo momento, a concorrência do biocombustível no cenário nacional. Em ambas as figuras (Figuras 1 e 2) este período está marcado pela área sombreada.

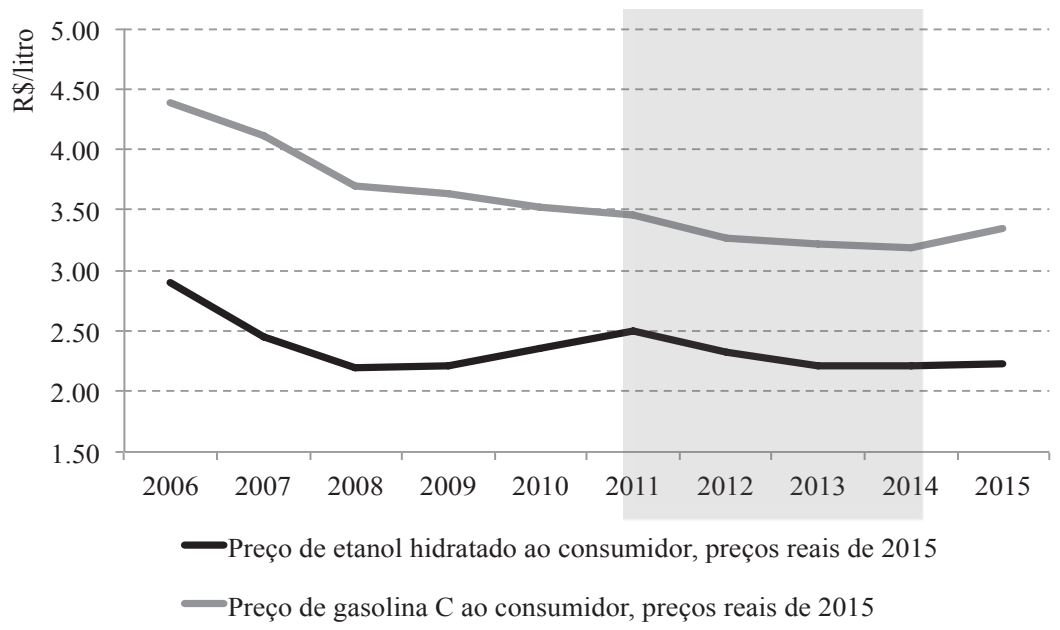

Figura 2 - Preços reais (2015) de etanol hidratado e gasolina C no Brasil, médias anuais de todos os Estados do país. Período: 2006 a 2015.

Fonte: ANP (2016); FGV (2016).

Em 2015 surge então a terceira fase, como uma tentativa de retorno do incentivo ao biocombustível. Entretanto, a motivação para esta mudança de política não foi apenas o incentivo ao etanol hidratado, mas também o grande endividamento da empresa estatal (responsá-

${ }^{2}$ O controle do preço da gasolina na economia brasileira foi justificado pelo governo como uma medida necessária para evitar a aceleração de um processo inflacionário (MENDONÇA, 2007; SERRANO, 2010; COLOMBER \& TAVARES, 2012; ERNST \& YOUNG TERCO, 2011; CERQUEIRA \& COSTA, 2011; COMBUSTÍVEIS, 2013). Entretanto, tal controle foi alvo de críticas, pois a manutenção do preço artificialmente baixo provocou, dentre outros efeitos, redução de lucro e até mesmo prejuízo incorrido pela empresa estatal que produz o combustível fóssil no país - a Petrobrás (COLOMBER \& TAVARES, 2012; AS PERDAS, 2012; MING, 2012; MING, 2013), além da perda de competitividade do biocombustível relativamente à gasolina (ERNST \& YOUNG TERCO, 2011; CERQUEIRA \& COSTA, 2011; BARROS, 2012; AS USINAS, 2013; GOLDEMBERG, 2013). 
vel pelo controle do preço do combustível, a Petrobrás), ${ }^{3}$ que arcou com toda a diferença entre o preço de importação do combustível e sua revenda no mercado doméstico na fase anterior. Esta mudança veio, concomitantemente, com uma brusca desvalorização do combustível fóssil no mercado mundial, como pode ser observado pela queda no preço de importação da gasolina na Figura 1. Assim, enquanto os demais países do mundo puderam se beneficiar de redução nos custos de produção devido à redução no preço do combustível fóssil, o Brasil foi na contramão deste processo, encarecendo este insumo. Portanto, em 2015, até os dias atuais (2016), o governo continua com o controle sobre o preço da gasolina A, mas num patamar superior ao preço de importação. Adicionalmente, retomou a Cide, imposto extinto em 2012, de maneira a ser este mais uma fonte de receita do governo para pagar os prejuízos produzidos em anos anteriores. Do lado da relação de preço do combustível fóssil com o renovável, como descrito na Figura 2, esta mudança na política aumentou a diferença entre os preços destes produtos, favorecendo o consumo do etanol hidratado no país, em relação a anos anteriores.

Portanto, este trabalho tem por objetivo identificar o impacto do controle do preço da gasolina A sobre o preço do etanol hidratado no país, considerando o período de $2006^{4}$ a 2015. Tal período é adequado para a análise, pois possibilita uma avaliação da nova abordagem política, que tornou o preço nominal da gasolina A praticado no Brasil como a principal variável controlada pelo governo brasileiro.

Além das estimativas de valores relacionados à intervenção que podem auxiliar formuladores de política na definição de suas estratégias, o trabalho traz como contribuição a identificação de um modelo empírico que incorpora características relevantes dos mercados de combustíveis no país e que tem o respaldo da teoria de organização industrial.

3 A Petrobrás foi fundada em 1953, com o objetivo de executar as atividades do setor petrolífero no país, em nome da União, Em agosto de 1997, a Petrobrás passou a atuar em um novo cenário de competição instituído pela Lei 9.478, que regulamentou a emenda constitucional de flexibilização do monopólio estatal do petróleo.

4 Foi considerado apenas o período posterior a 2006 para esta análise, uma vez que uma condição essencial para a interferência do preço da gasolina sobre o preço do etanol hidratado é a existência de uma frota de veículos flexfuel no país, o qual apenas começou a ser comercializado em 2003. 
O presente trabalho está organizado de forma que no próximo item (item 2) tem-se uma apresentação dos métodos e dados utilizados neste estudo e no item 3 estão apresentados e discutidos os resultados, seguidos das conclusões no último item deste trabalho.

\section{Abordagem metodológica}

Nesta seção, inicialmente buscou-se identificar qual seria o preço da gasolina C no Brasil na ausência da interferência governamental, para o período de 2006 a 2015 (seção 2.1). Estes resultados foram obtidos e apresentados considerando os preços médios ponderados para todo o país. A seguir, dada a necessidade de identificação da influência do controle de preço da gasolina C ( $75 \%$ gasolina A $+25 \%$ etanol anidro) no mercado de etanol hidratado para o modelo elaborado, é apresentado um modelo teórico para explicar esta relação (seção 2.2), assim como o procedimento econométrico e dados utilizados utilizado para estimar os seus coeficientes (seção 2.3). A estimativa deste modelo utilizou os dados individualizados para todos os estados do país.

\subsection{Modelo para estimar o preço dos combustíveis no país sem o controle no preço da gasolina $A$}

Uma vez que o país foi importador líquido de gasolina, utilizou-se o preço de importação do produto, descrito na Figura 1, como sendo o preço que o mercado deveria ter pago pela gasolina A naquele ano. ${ }^{5}$ Considerando-se, ainda, que o impacto do controle do preço é sentido pelos consumidores, deve-se estimar o preço equivalente da gasolina $\mathrm{C}^{6}$ nos níveis do preço internacional da gasolina A. Para isto, ao preço da gasolina A soma-se: o preço do etanol anidro, na

\footnotetext{
5 Não há outros custos incidentes uma vez que a tarifa de importação da gasolina, desde 2001, encontra-se zerada pelo país. Quando o valor importado de gasolina A no país foi inferior a US\$5 milhões (isto ocorreu entre 2007 e 2009), foi utilizado o valor unitário da importação mundial (UNCTSD, 2014), uma vez que o baixo valor de importação pode ter causado distorção no valor unitário da importação do Brasil.

6 Segundo a Agência Nacional de Petróleo, Gás Natural e Biocombustível - ANP (órgão responsável pela regulamentação, fiscalização e contratação desse setor), o preço da gasolina A divulgado no país inclui os impostos federais, como o PIS/PASEP e COFINS. Assim, somando o valor destes impostos aos preços de importação, obtém-se um preço estimado da gasolina A que pode ser comparado àquele praticado no país.cializado em 2003.
} 
proporção pela qual este é misturado à gasolina em cada ano; o imposto estadual que incide sobre o combustível (ICMS); e as margens de comércio e transporte. Uma vez que o valor do ICMS é calculado por dentro, ou seja, levando em conta o preço da gasolina $\mathrm{C}$ paga pelo consumidor final, a fórmula utilizada para formação deste preço é descrita na Equação (1):

$$
P c g=\frac{M+\left(P p a * \text { Part }_{a}\right)+\left(1-\text { Part }_{a}\right) * P p g}{1-t}
$$

onde: $M$ é a margem de comércio e transporte e outros custos considerados; ${ }^{7}$ Part $_{a}$ é a participação do anidro na gasolina; Ppg é o preço da gasolina A no mercado doméstico ou, quando o preço estimado considerar a ausência de intervenção do governo, este preço foi substituído pelo preço da gasolina A importada $\left(\mathrm{Ppg}_{M}\right)$, somado aos impostos federais, e $t$ representa o impostos que incidem por dentro, no caso, o ICMS.

O valor da margem $(M)$ foi obtido como a diferença entre o preço da gasolina $\mathrm{C}$ observado e o preço estimado, como descrito anteriormente, mas sob as condições observadas, ou seja, com o preço da gasolina A aplicado no país, assim como os impostos aplicados, em cada ano. Esta margem foi utilizada para calcular o preço da gasolina $\mathrm{C}$, mas agora tomando como base o preço internacional da gasolina A. Assim, tem-se o quanto o preço da gasolina $\mathrm{C}$ no país foi artificialmente reduzido ou aumentado pelo governo em relação às condições de livre comércio no mercado de refino de petróleo.

Para estimar a interferência do preço da gasolina $\mathrm{C}$ sobre o preço ao consumidor do etanol hidratado $(P c h)$, é necessário conhecer o comportamento observado entre estes preços no período, o que é descrito na seção posterior (2.2). O impacto sobre o preço ao produtor de etanol hidratado é igual ao novo preço ao consumidor ( $P c h)$ subtraído das margens de comércio e transporte, conforme descrito na Equação (2):

$$
P p h=P c h-m
$$

Além dos custos de comércio e transporte, algum outro imposto incidente sobre o preço da gasolina $\mathrm{C}$ não especificado também está incluído nesta variável. Também as diferenças de preços observadas devido ao mercado não perfeitamente competitivo do varejo da gasolina, caso existam, estão inseridas nesta variável. Conforme identificado por Nunes \& Gomes (2005), o mercado varejista de gasolina C pode apresentar imperfeições. 
$\mathrm{Na}$ maioria dos casos, o ofertante de etanol hidratado e de etanol anidro é o mesmo, e a decisão de qual produto ofertar depende do preço relativo entre estes dois produtos. Assim, os preços do etanol hidratado e do etanol anidro são mantidos numa determinada relação técnica $(\theta)$ para que ambos possam ser ofertados, conforme descrito na Equação (3):

$$
P p a=\theta * P p h
$$

Portanto, o impacto do preço ao produtor de etanol hidratado é também transferido ao preço de etanol anidro. Como a formação do preço da gasolina C (Equação 1) depende do preço de etanol anidro $(\mathrm{Ppa})$, este foi alterado pelo movimento causado sobre o preço da gasolina $\mathrm{C}$ ao considerar o preço da gasolina $\mathrm{A}$ como o preço de importação deste produto, tem-se um processo interativo. Assim, o novo preço estimado de etanol anidro (Ppa) é utilizado na formação do preço da gasolina C (Equação 1), gerando um novo choque que, novamente, impacta os preços de etanol hidratado ao consumidor (pela elasticidade de transmissão entre os preços da gasolina $C$ para o etanol hidratado - $\sigma \mathrm{l}$, descrita na próxima seção), de etanol hidratado ao produtor (Equação 2) e, mais uma vez, do etanol anidro (Equação 3). Este valor foi calculado até se atingir um equilíbrio observado para cada ano analisado. A Figura 3 descreve este procedimento interativo de equilíbrio entre os preços dos combustíveis.

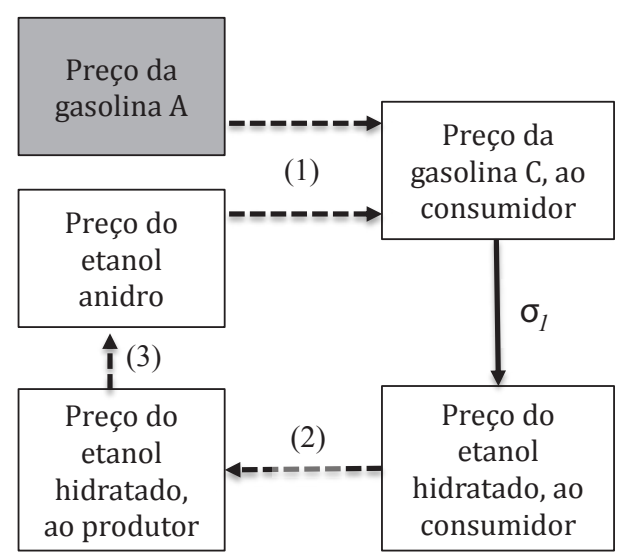

Figura 3 - Processo interativo da formação de preços no mercado de combustíveis para veículos leves no Brasil 
As linhas pontilhadas na Figura 3 indicam os cálculos dos preços descritos nas Equações de (1) a (3) e a linha sólida a estimativa da elasticidade preço de impacto do preço da gasolina $\mathrm{C}$ sobre o preço do etanol hidratado, conforme estimado pelo método descrito nas próximas seções (2.2 e 2.3). O choque é dado na caixa sombreada, onde o preço pago pela gasolina A em cada ano analisado no Brasil foi substituído pelo correspondente preço de importação deste produto.

Os valores da CIDE em cada ano foram obtidos em Brasil (2016a). A participação do anidro na gasolina foi alterada algumas vezes no período analisado, tendo sido obtida em Brasil (2016b). Os preços ao consumidor de gasolina $\mathrm{C}(P c g)$ e de etanol hidratado $(P c h)$ foram obtidos junto à Agência Nacional do Petróleo ou ANP (2016), considerando os preços médios ponderados já assim definidos para o país pela ANP. Quando foi utilizada na Equação (1) o preço da gasolina A praticada no mercado internacional $\left(\mathrm{Ppg}_{M}\right)$, o preço de importação deste produto foi obtido em Brasil (2016c), e, alternativamente, em UNCTSD (2014) nos anos em que o volume/valor de importação de gasolina A no Brasil foi baixo, comprometendo o valor unitário da importação brasileira. O preço recebido pelo produtor do anidro (Ppa) foi obtido pelo Centro de Estudos Avançados em Economia Aplicada - CEPEA (USP, 2016). Como os valores do ICMS diferem entre os estados e não há uma média nacional já estabelecida para esta variável, utilizou-se uma média ponderada pelo consumo dos combustíveis para os valores de cada estado obtidos em Secretaria (2016).

\subsection{Modelo teórico de formação do preço no mercado do etanol hi- dratado}

Conforme descrito na Figura 3, é necessário conhecer também a estimativa da elasticidade preço de impacto do preço da gasolina C sobre o preço do etanol hidratado. Esta seção descreve o modelo de formação do preço do etanol hidratado de maneira a se poder conhecer esta variável.

A derivação convencional da oferta de etanol hidratado resulta em uma função que depende de seus próprios preços, do preço de produtos alternativos no seu processo produtivo - como o etanol anidro e o açúcar, bem como de seus insumos, que no caso seria a cana- 
de-açúcar, responsável por cerca de $60 \%$ dos custos de obtenção do hidratado. Um pressuposto básico à definição da oferta de etanol hidratado (Sh) é que esta é positivamente relacionada ao preço recebido pelo produtor desse mesmo produto $(\mathrm{Pph})$ e negativamente relacionada aos preços de produtos alternativos, como o preço ao produtor de etanol anidro $(P p a)$ e do açúcar (Ppac), sendo esses últimos obtidos a partir da mesma matéria prima. Entretanto, a variável Ppac foi suprimida do modelo de oferta de etanol hidratado no Brasil, delineado para a presente pesquisa, uma vez que estudos conduzidos anteriormente têm identificado que tal variável não tem sido capaz de explicar a oferta no mercado de etanol (Costa et al., 2015). ${ }^{8}$ Adicionalmente, o modelo assume que o preço ao produtor pode ser considerado como o preço ao consumidor $(P c h)$ subtraído da margem de comercialização $(m)$, que inclui os custos com despesas para o comércio e transporte. Assim, considerou-se que uma equação de oferta do etanol hidratado $(S h)$ pode ser modelada como uma função multiplicativa dos preços, linearizada pela aplicação de logaritmos, resultando na seguinte expressão:

$$
S h=\alpha_{1}(P c h-m)+\alpha_{2} P p a
$$

onde: $(S h)$ oferta de etanol hidratado; Pch é o preço do etanol hidratado ao consumidor; Ppa é o preço do etanol hidratado pago ao produtor e m é a margem de comercialização. A forma linear assume que as variáveis já estão expressas em seus logaritmos.

Já o modelo de demanda de etanol hidratado (Dh) no Brasil é descrito em vários estudos (SOUZA, 2010; FREITAS \& KANEKO, 2011; CAROPREZO, 2011; CARDOSO \& BITTENCOURT, 2012), como apresentado na Equação (5) a seguir:

$$
D h=\partial_{1} P c h+\partial_{2} P c g+\partial_{3} F \text { flex }+\partial_{4} Y
$$

onde $P c g$ é o preço da gasolina $\mathrm{C}$ ao consumidor; $\mathrm{Y}$ indica a renda da economia e Fflex, que representa a frota de veículos flex existente no mercado. Também nessa expressão, a forma linear assume que as variáveis já estão expressas em seus logaritmos.

8 Outros autores também observaram a não significância do preço do açúcar sobre a oferta de eta-
nol. A explicação para este comportamento é o percentual relativamente baixo de cana-de-açú-
car que pode ser convertida entre etanol e açúcar no Brasil: cerca de $10 \%$, segundo Farina (2013). 
Espera-se, para a equação de oferta, um sinal positivo para o coeficiente $\alpha_{1}$ e um sinal negativo para o coeficiente $\alpha_{2}$. Na Equação (5), os sinais esperados para os coeficientes $\partial_{2}, \partial_{3}$ e $\partial_{4}$ são positivos, uma vez que para um aumento nas variáveis relacionadas a estes coeficientes, espera-se um incremento na demanda por etanol hidratado. Já para o coeficiente $\partial_{1}$ espera-se sinal negativo, uma vez que um aumento no preço de etanol hidratado ao consumidor induz a uma redução na demanda pelo produto, ou seja, trata-se de um bem normal.

Assumindo - como observado para a maior parte do período analisado - que não se faz necessária a importação no mercado global e que o consumo de etanol hidratado é totalmente atendido pela produção do país, o equilíbrio é dado pela igualdade entre a oferta e a demanda domésticas do produto. Além disto, para o mercado de bioetanol combustível, Beiral (2011) avaliou o poder de mercado dos produtores brasileiros de etanol e por parte das distribuidoras de combustíveis neste mercado no período de 2003 a 2010, quando ocorreram fusões e aquisições entre produtores e distribuidoras de combustíveis automotivos. Utilizando a ferramenta da Nova Organização Industrial Empírica (NEIO), Beiral (2011) concluiu que os produtores e distribuidores de etanol combustível não exerceram efetivamente poder de mercado no período, sendo que os parâmetros estimados indicaram uma estrutura de mercado mais próxima da concorrência perfeita, em que o preço é definido pela igualdade entre a oferta e a demanda.

Assim, igualando-se as Equações (4) e (5) e procedendo às transformações algébricas necessárias para expressar o modelo na forma de uma equação na sua forma reduzida, de forma que o preço do etanol hidratado é uma variável endógena, chega-se à Equação (6):

$$
\begin{gathered}
\text { Pch }=\frac{\partial_{2}}{\left(\alpha_{1}-\partial_{1}\right)} \text { Pcg }+\frac{\partial_{3}}{\left(\alpha_{1}-\partial_{1}\right)} \text { Fflex }+\frac{\partial_{4}}{\left(\alpha_{1}-\partial_{1}\right)} Y+ \\
\frac{\alpha_{1}}{\left(\alpha_{1}-\partial_{1}\right)} \text { margem }-\frac{\alpha_{2}}{\left(\alpha_{1}-\partial_{1}\right)} \text { Ppa }
\end{gathered}
$$

Considerando os sinais esperados para os coeficientes da oferta e demanda, acredita-se que todas as variáveis relacionadas no modelo descrito na Equação (6) tenham relação positiva com o preço etanol hidratado. 
A seguir (item 2.3) descrevem-se os procedimentos econométricos, juntamente com os dados utilizados para se estimar a Equação (6) no presente trabalho.

\subsection{Modelo empírico e econométrico}

A Equação (6) descreve o modelo na sua forma reduzida, obtida a partir da igualdade entre as Equações (4) e (5). Entretanto, há a possibilidade de problemas de multicolinearidade entre as variáveis renda $(Y)$ e frota flexfuel (Fflex), uma vez que o crescimento da frota depende do crescimento de renda da população. A multicolinearidade entre as variáveis preço ao produtor do etanol anidro $(P p a)$ e o preço ao consumidor da gasolina $(P c g)$ também é esperada, uma vez que o preço da gasolina é formado em parte pelo preço do etanol anidro. ${ }^{9}$ Além disto, supõe-se que toda variação no preço ao consumidor do etanol hidratado decorre de mudanças no preço ao produtor e não na margem de comercialização, o que é uma pressuposição razoável, considerando o tempo relativamente curto considerado para a análise.

Desta forma, o modelo descrito na Equação (6) foi simplificado para a forma descrita na Equação (7), que expressa a forma econométrica utilizada para estimar a equação de formação do preço ao consumidor de hidratado no Brasil.

$$
\ln P c h_{i, t}=\sigma_{0}+\sigma_{1} \ln P c g_{i, t}+\sigma_{2} \ln Y_{i, t}+\mu_{i, t}
$$

onde os subscritos $i$ e $t$ indicam, respectivamente, a variável crosssection e o ano analisado. Ou seja, foi utilizado um modelo em painel para a estimativa feita neste trabalho. Os cortes seccionais foram definidos em função dos estados do país e o período foi de 2006 a 2015, período no qual os veículos flexfuel já estavam estabelecidos no país.

\footnotetext{
${ }^{9}$ A relação entre estas duas variáveis pode ser observada na Equação (5), descrita no próximo item.
} 
Estimativas do modelo de formação do etanol hidratado utilizando modelos semelhantes ao descrito anteriormente foram realizadas anteriormente por Bacchi (2005) e Cavalcanti (2011). No trabalho de Bacchi (2005), empregando análise de série temporal a dados mensais de julho de 2001 a agosto de 2004, identificou-se que as variações do preço da gasolina $\mathrm{C}$ ao consumidor apresentaram efeito imediato e de magnitude relativamente elevada (elasticidade de 1,12) sobre o preço do etanol hidratado neste mesmo segmento. Entretanto, ao contrário do realizado neste estudo, o período utilizado por este autor não permitiu avaliar o efeito do aumento da participação de veículos flexfuel maior do que o de veículos movidos exclusivamente a gasolina ou a etanol na frota automotiva brasileira. Isso é importante, uma vez que esta nova realidade, conforme descrito por Costa \& Guilhoto (2011), aumentou, como esperado, a competitividade entre os combustíveis fóssil e renovável. Consequentemente, a expectativa é de aumento na elasticidade de substituição dos produtos e transmissão de preços diferenciada. Já utilizando dados anuais para um período mais recente, de 2002 a 2009, Cavalcanti (2011) estimou um modelo de formação do preço de etanol hidratado em função do preço da gasolina e dos preços defasados de ambos os combustíveis. A elasticidade de transmissão do preço da gasolina para o etanol identificada no trabalho foi de 1,64. Mas também neste caso, a consideração de períodos anteriores à expansão de veículos flexfuel, introduzido em 2003, pode ter prejudicado a análise. Além disto, em ambos os trabalhos revistos não foram consideradas as diferenças existentes entre os estados do país. A inclusão dos dados em painel com os estados compondo variáveis do modelo é importante, uma vez que os preços ao consumidor diferem entre eles, tanto para o etanol hidratado como para a gasolina. Adicionalmente, a relação entre os preços destes dois combustíveis é também diferente, principalmente porque o imposto estadual (ICMS) que incide sobre ambos os combustíveis também difere entre os estados. Desta maneira, acredita-se que as estimativas realizadas neste estudo possam representar de maneira mais acertada o comportamento destes preços no período analisado.

Para estimar os valores das elasticidades a partir da Equação (6), inicialmente as variáveis são tomadas nos seus logaritmos. Procedendo desta maneira, os valores dos coeficientes podem ser interpretados como sendo as variações percentuais, ou seja, as elasticidades. Por utilizar o modelo econométrico de dados em painel, foi necessário 
proceder ao teste de Haussman, com objetivo de identificar se o modelo deveria ser tratado como de efeitos fixos ou variáveis. Foi também utilizado o teste de Woolridge para identificar possíveis problemas de auto correlação entre os dados.

O modelo foi estimado considerando robustez dos erros e os coeficientes estimados foram analisados considerando seu intervalo de confiança, de maneira a dar mais consistência às análises feitas a partir dos mesmos. A pequena extensão temporal utilizada, assim como o controle de preço utilizado pelo governo, indicam a estacionariedade das séries temporais utilizadas.

Os preços ao consumidor de gasolina $\mathrm{C}(\mathrm{Pcg})$ e de etanol hidratado (Pch) foram obtidos junto à Agência Nacional do Petróleo ou ANP (2016). Para a variável renda foram utilizadas como proxy duas variáveis: PIB estadual (PIB) e o PIB estadual per capita (PIBc), ambos obtidos em Brasil (2016d). Assim, foram testados dois modelos empíricos, um para cada variável. Todas estas variáveis monetárias foram deflacionadas pelo índice geral de preços (IGP-DI) da economia brasileira (FGV, 2016). Para a série temporal consideraram-se as médias anuais ou dados anuais, quando a estatística é assim definida, para o período de 2006 a 2015.

\section{Resultados e discussão}

O trabalho avaliou a magnitude da intervenção governamental sobre os preços da gasolina e a intensidade pela qual os preços dos combustíveis ao consumidor e os preços de etanol ao produtor foram afetados. Para isto, foram identificados: o impacto do preço da gasolina sobre o preço do etanol hidratado; a proporção da interferência do governo no preço da gasolina no país, e o impacto da interferência do governo no preço da gasolina sobre o preço do etanol. A primeira questão é respondida na seção 3.1, com base no método e dados apresentados na seção 2.3. Já as duas últimas questões, foram obtidas conjuntamente na seção 3.2, considerando o método e dados descritos na seção 2.1. 


\subsection{Estimativas da formação de preço do etanol hidratado no Brasil}

Os resultados da estimativa da equação que descreve a formação do preço do etanol hidratado no país (Equação 7) são apresentados na Tabela 1. Conforme descrito no método, foram testados dois modelos empíricos. O modelo 1 utilizando o PIB estadual e o modelo 2 o PIB estadual per capita, como variáveis alternativas para proxy da renda. Para ambos os modelos, o teste Haussman indicou o modelo econométrico de efeitos fixos como mais adequado. Segundo esse teste, o modelo de efeitos aleatórios (hipótese nula deste teste) foi rejeitado a um nível de significância menor do que $1 \%$, com valor do teste $\chi^{2}$ de 11,6 para o modelo 1 e a um nível de significância de $5 \%$, com valor do teste $\chi^{2}$ de 8,4 no modelo 2 . A presença de autocorrelação foi descartada pelo teste de Woolridge, a um nível de significância de $1 \%$ também em ambos os modelos, com valor do teste F de 174 no modelo 1 e de 199,8 no modelo 2. Já os coeficientes de ajustamento (R2) dentro das unidades, entre as unidades e total teve uma variação maior entre os modelos 1 e 2. Enquanto o modelo 1 apresentou um melhor ajustamento, de 55\%, 40\% e $11 \%$, respectivamente, para o modelo 2 estes valores foram de $55 \%$, 3\% e 3\%, respectivamente. Em ambos os modelos, o valor do teste $\mathrm{F}$ foi significativo ao nível de $1 \%$ e os sinais das variáveis tiveram comportamento conforme esperado e com valores próximos para ambos os modelos estimados, o que indica robustez para os valores dos coeficientes estimados. Ainda neste sentido, utilizando períodos menores de tempo na série utilizada, os valores dos coeficientes foram semelhantes aos descritos na Tabela 1. Entretanto, os coeficientes estimados no modelo 1 , onde a variável PIB foi utilizada como proxy da renda, apresentaram níveis de significância melhores, abaixo de $1 \%$, do que aqueles descritos para o modelo 2. Esta verificação, juntamente com os menores valores de ajustamento (R2) para o segundo modelo, foram os determinantes da escolha dos valores do modelo 1 para a análise realizada neste estudo. 
Tabela 1 - Estimativa do modelo de formação do preço de etanol hidratado $(P c h)$ no Brasil, 2006-2015

\begin{tabular}{|c|c|c|c|c|c|}
\hline & \multirow[t]{2}{*}{ Coeficiente } & \multicolumn{2}{|l|}{$\begin{array}{l}\text { Elasticidades } \\
\text { estimadas }\end{array}$} & \multicolumn{2}{|c|}{$\begin{array}{l}\text { Elasticidades com intervalo de con- } \\
\text { fiança de } 95 \% \text { de probabilidade }\end{array}$} \\
\hline & & Modelo 1 & Modelo 2 & Modelo 1 & Modelo 2 \\
\hline Constante & $\sigma_{0}$ & $-2,37^{\star}$ & $-0,469^{\star * \star}$ & $-3,95$ a $-0,79$ & $-1,03$ a 0,09 \\
\hline $\begin{array}{l}\text { Preço ao consumidor de } \\
\text { gasolina (Pcg) }\end{array}$ & $\sigma_{1}$ & $0,79^{*}$ & $0,68^{*}$ & 0,65 a 0,94 & 0,57 a 0,79 \\
\hline $\begin{array}{l}\text { Produto Interno Bruto per } \\
\text { capita }(P I B C)\end{array}$ & $\sigma_{2}$ & & $0,19^{\star *}$ & & 0,047 a 0,34 \\
\hline Produto Interno Bruto (PIB) & $\sigma_{2}$ & $0,20^{*}$ & & 0,08 a 0,33 & \\
\hline Teste F do modelo & & $140^{*}$ & $148^{*}$ & & \\
\hline \multicolumn{6}{|l|}{ Teste Haussman - } \\
\hline$\chi^{2}$ & & $11,6^{*}$ & $8,4^{* *}$ & & \\
\hline Teste Woolridge - teste $F$ & & $174^{*}$ & $199,8^{*}$ & & \\
\hline R2 dentro das unidades & & $55 \%$ & $55 \%$ & & \\
\hline
\end{tabular}

*Indica nível de significância de $1 \%$. ${ }^{* *}$ Indica nível de significância de 5\%.*** Indica nível de significância de $10 \%$

Assim, considerando os valores dos coeficientes estimados para o modelo 1 , verifica-se que o aumento de $1 \%$ no preço da gasolina $\mathrm{C}$ ao consumidor causaria um aumento equivalente entre $0,79 \%$ no preço do etanol hidratado na bomba, podendo variar entre $0,65 \%$ e $0,94 \%$, considerando um nível probabilidade de $95 \%$. Este resultado mostrou que a resposta do preço do etanol hidratado a mudanças no preço da gasolina $C$ foi menor do que aquelas obtidas por Bacchi (2005) e Cavalcanti (2011), que foram de $1,12 \%$ e 1,64\%, respectivamente. As consequências destas diferenças nos resultados obtidos foram discutidas no próximo item.

\subsection{Estimativa do controle de preço da gasolina e impactos sobre os} preços de etanol

A Figura 4 descreve os preços observados e estimados da gasolina $\mathrm{C}$ e do etanol hidratado ao consumidor, em cada ano analisado, para os preços médios praticados no Brasil. ${ }^{10}$ Os preços estimados descritos nesta figura foram calculados considerando: a magnitude da intervenção do governo no preço da gasolina no país no período de 2006

${ }^{10}$ Foram utilizados os preços médios ponderados pelo consumo estimados pela ANP para todo território nacional. 
a 2015; o processo interativo onde os preços estimados para o etanol interferem novamente no preço da gasolina $\mathrm{C}$, conforme descrito na Figura 3 e; o valor da elasticidade de transmissão de preço da gasolina para o etanol hidratado estimado anteriormente. Uma vez que foram utilizados os valores estimados desta elasticidade, esta figura apresenta os limites do intervalo de confiança obtidos para a elasticidade preço da gasolina sobre o preço do etanol hidratado descrito na Tabela 1: 0,65 e 0,94. Verifica-se que a variação observada nestas estimativas em função deste intervalo de confiança causa alterações muito pequenas no preço estimado para ambos os combustíveis, per-manecendo grande as diferenças entre estas estimativas e os preços praticados no país. Os preços da gasolina $\mathrm{C}$ e do etanol hidratado ficaram, em média, cerca de 10\% acima do preço que deveria ter vigorado nos períodos de 2006-10 e 2015 e -7\% no período 2011-14. Utilizando o valor estimado desta elasticidade, que é de $0,79 \%$, os preços estimados situam-se entre aqueles descritos nas linhas pon-tilhadas da Figuras 4.

Observa-se que, até 2010 e em 2015, o preço praticado no mercado doméstico foi superior àquele esperado para uma situação onde 0 governo não intervém no preço do combustível fóssil, para ambos os combustíveis. Este comportamento já era esperado para o preço da gasolina C, uma vez que a Figura 1 mostrou que o preço da gasolina A, principal componente deste combustível, foi superior no mercado doméstico naqueles mesmos anos. Entretanto, a Figura 4 mostra o quanto o consumidor pagou, até 2010 e em 2015, e deixou de pagar entre 2011 e 2014 pelo efeito deste controle.

A diferença visualizada na Figura 4 entre os preços praticados (ou observados) e os estimados pode ser interpretada como o valor do subsídio. Entretanto, estes valores devem ser interpretados de maneira diferenciada: enquanto no primeiro (2006-2010) e terceiro (2015) períodos, o subsídio foi dirigido ao estímulo para o consumo de etanol hidratado em detrimento ao consumo do combustível fóssil, no segundo período (2011-2014), o subsídio foi orientado ao desestímulo do biocombustível. 


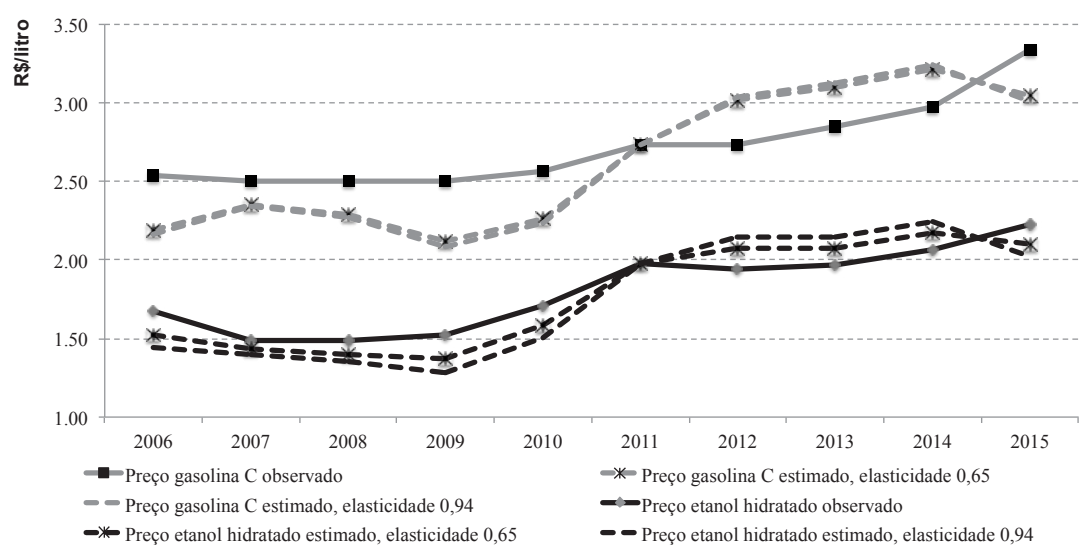

Figura 4 - Preços médios do país, observados e estimados para a ausência de interferência governamental, da gasolina $\mathrm{C}$ e do etanol hidratado pago pelo consumidor. Período: 2006 a 2015

A influência do preço da gasolina ao consumidor como subsídio ao etanol hidratado, até 2010 e após 2015, ou taxação àquele mesmo produto, de 2011 a 2014, pode ser observada, na Figura 5, através dos respectivos preços ao produtor de etanol hidratado e anidro em cada ano. Estes preços foram estimados conforme descrito nas Equações (2) e (3), respectivamente, para o etanol hidratado e o anidro. Para estas estimativas foram considerados: (i) os novos preços de etanol hidratado ao consumidor estimados sem o controle do governo na gasolina; (ii) as margens de comércio e transporte observadas em cada ano para o etanol hidratado; e (iii) a relação estabelecida entre os preços ao produtor de etanol hidratado e anidro. No item (iii) o preço do etanol anidro está relacionado ao preço do etanol hidratado, assumindo que o produtor de etanol decide o mix entre estes dois produtos em função do preço relativo entre eles $(\theta)$. Para o período utilizado neste estudo, o preço de etanol anidro ao produtor foi $114 \%$ do preço do etanol hidratado. Assim, esta relação foi utilizada para identificar o impacto sobre o preço de etanol anidro ao produtor. Observa-se nesta figura que, assim como observado para os preços ao consumidor, os preços estimados para o etanol hidratado ou anidro são mais distantes daqueles praticados quando se considera o limite superior do intervalo de confiança para o valor da elasticidade preço da gasolina no etanol hidratado, que foi de $0,94 \%$. Os preços estimados mais próximos aos praticados foram obtidos utilizando o limite inferior do intervalo de confiança para esta elasticidade $(0,65 \%)$, e 
os preços estimados, utilizando a elasticidade de $0,79 \%$, ficam entre aqueles estimados considerando os limites do intervalo de confiança.

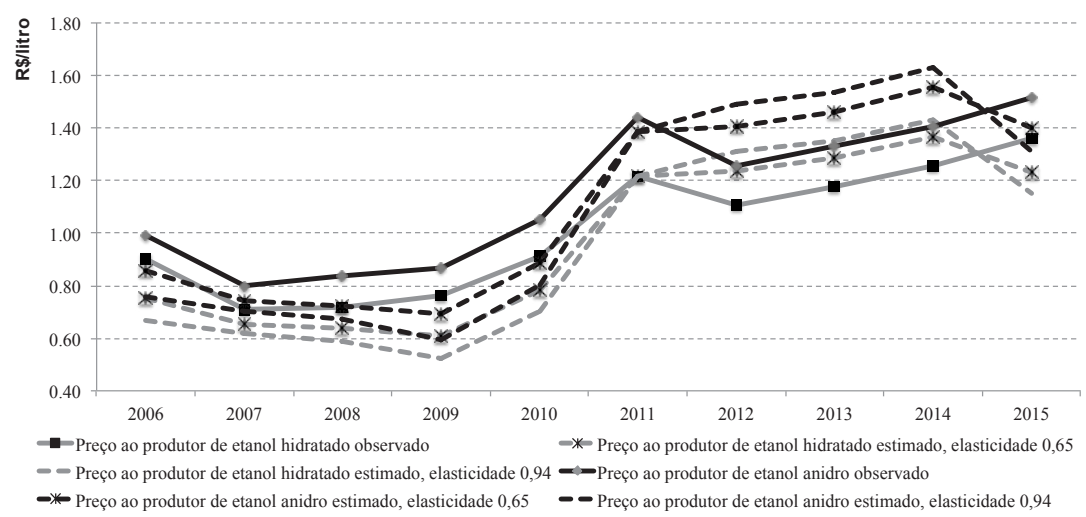

Figura 5 - Preços ao produtor do etanol hidratado e anidro, observados e estimados considerando a ausência de interferência governamental. Período: 2006 a 2015

Portanto, nas estimativas apresentadas na Figura 5 tem-se que o preço que o produtor do etanol hidratado e do etanol anidro teriam recebido, sem a interferência do governo federal no preço da gasolina no país entre 2006 e 2010 e em 2015, é inferior ao observado, em média, 17\%. Quando se consideram os volumes consumidos, observados e estimados para os preços sem a intervenção, assim como a diferença nos preços praticados, esta diferença representa um aumento de receita de cerca de $\mathrm{R} \$ 5,0$ bilhões em 2009, 2010 e em 2015 para o produtor de biocombustível (anidro e hidratado). Conforme se observa nas Figuras 4 e 5, aqueles anos (2009, 2010 e 2015) foram quando o controle do preço da gasolina significou o maior incentivo ao etanol. Entretanto, entre 2011 e 2014 os preços de etanol hidratado e anidro ao produtor foram deprimidos em cerca de $10 \%$. Isto significou uma perda de receita para o produtor de etanol no país de cerca de $\mathrm{R} \$ 4,0$ bilhões em cada um dos anos de 2012, 2013 e 2014. ${ }^{11}$

A variação na taxa de câmbio é também importante para estimar a variação entre os preços praticados e estimados da gasolina. Isto ocorre porque o combustível fóssil é uma commodity cujo preço no

\footnotetext{
${ }^{11}$ Neste cálculo foram considerados os valores das elasticidades preço e preço cruzada da demanda de etanol de $-3,23$ e 3,38, respectivamente, e das elasticidades preço e preço cruzada da demanda de gasolina de $-0,83$ e 0,64 , respectivamente. Estas elasticidades foram estimadas por Costa \& Burnquist (2014).
} 
mercado doméstico, sem intervenção, é dado pelo preço formado no mercado internacional. E este, ao ser internalizado, também varia no mesmo sentido das diferenças cambiais. Assim, entre 2006 e 2008, a taxa de câmbio ficou próxima ao patamar de 2 (Reais por Dólar). A partir de 2008, a taxa reduziu em função do grande fluxo de dólares na economia brasileira, alcançando 1,67 em 2011, mas voltando ao patamar observado antes de 2008, em 2012. Desta maneira, o comportamento da taxa de câmbio amenizou o subsídio que poderia ter ocorrido no ano de 2008 para o produtor de etanol e acentuou o impacto do subsídio para a gasolina observado em 2012 e 2013 (Com mudança, 2013). A partir de 2013 o cenário foi de valorização ainda maior do câmbio, respondendo, também por este motivo uma variação percentual entre os preços da gasolina com e sem o controle de preços do governo ainda maior. Em 2015, a taxa de câmbio média do país ficou em 3,38. Uma vez que, neste ano, o governo usou uma política de aumento no preço da gasolina $\mathrm{A}$, esta desvalorização da moeda doméstica em 2015 atuou a favor da política governamental. Mas a grande desvalorização do preço do petróleo e, consequentemente, da gasolina no mercado internacional, foi uma força contrária e este esforço naquele mesmo ano. Daí o grande valor de subsídio observado para o produtor de etanol em 2015.

Uma vez que a gasolina $C$ e o etanol hidratado são produtos substitutos para o consumo, a relação entre o preço dos mesmos é outra variável importante a ser considerada, pois influencia a variação da demanda de um combustível em relação ao outro. A Figura 6 mostra como o preço ao consumidor do etanol hidratado se comportou em relação ao preço da gasolina $\mathrm{C}$, observados e estimados, em todos os anos analisados. Neste caso, quanto menor o preço relativo do etanol hidratado, maior a preferência dos consumidores por este combustível, em detrimento à gasolina. Segundo a UNICA (2016), o consumo de etanol é economicamente vantajoso para o consumidor quando esta relação é inferior a $70 \%$. Observa-se nesta figura que esta relação ficou abaixo, mas muito próxima, dos $70 \%$; a exceção ocorreu do ano de 2011, devido à quebra da safra da cana-de-açúcar naquele ano, o que implicou a elevação do preço de etanol.

Já considerando os preços estimados para uma situação sem o controle do governo no preço da gasolina (linha tracejada na Figura 6), observa-se também dois períodos distintos: um de 2006 a 2010 e pós 2015; e outro entre os anos de 2011 e 2014. Enquanto no perío- 
do até 2010 e em 2015 os preços estimados indicaram um aumento na relação do preço do etanol hidratado sobre o preço da gasolina, entre 2011 e 2014 esta relação diminuiu para os preços estimados em relação ao que foi observado no país. Ou seja, o controle do preço da gasolina A no país reduziu a relação preço etanol hidratado sobre preço gasolina no primeiro período, melhorando a competitividade do biocombustível e apresentou efeito contrário no segundo período (2011-2014), corroborando com os resultados identificados anteriormente.

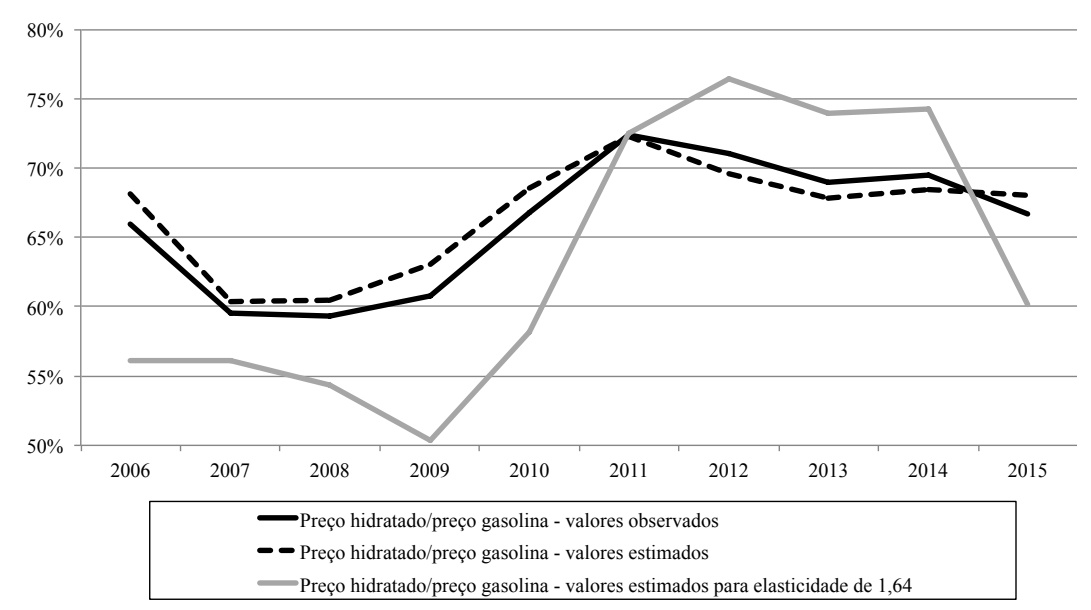

Figura 6 - Percentual do preço ao consumidor do etanol hidratado em relação ao preço da gasolina $\mathrm{C}$, observados e estimados sem a interferência do governo, para o valor da elasticidade obtida neste estudo $(0,79)$ e em outros estudos $(1,64)$. Dados para o Brasil no período: 2006 a 2015

Entretanto, como pode ser também observado na Figura 6, este resultado seria diferente se o valor da elasticidade preço da gasolina sobre o preço do etanol hidratado fosse maior do que um (1), resultado este obtido em outros estudos conforme descrito na seção 2.3. Neste caso (elasticidade maior do que 1), no período onde o controle do preço da gasolina funcionava como subsídio ao biocombustível, sem esta intervenção, a relação do preço do etanol hidratado sobre o preço da gasolina $\mathrm{C}$ seria menor do que a relação que foi observada no período. Este resultado é oposto ao observado, utilizando o valor da elasticidade obtida neste estudo e contra intuitivo, uma vez que ele indica que: sem a política de subsídio ao biocombustível, o preço relativo de biocombustível ficaria mais atraente. 
Da mesma forma, caso estivessem corretos os valores das elasticidades descritas na revisão observadas em outros estudos $(1,12 \%$ e 1,64\%), a eliminação do subsídio à gasolina entre 2011-2014 tornarse-ia, ainda assim, o consumo deste combustível mais atrativo do que o consumo do combustível renovável concorrente. Esta não é uma pressuposição aceitável, visto que o mercado do etanol hidratado não recebeu subsídio do governo naquele ano e, mesmo sob condições de preços da gasolina artificialmente deprimidos, ofertou o produto a preços concorrenciais. Assim, o mais razoável é supor que, deixando de controlar o preço atual da gasolina, este preço seria elevado e o preço do etanol hidratado seria mais competitivo do que o do combustível fóssil. Uma vez que este foi o resultado obtido neste estudo, indicado pela elasticidade de 0,79 do preço da gasolina $\mathrm{C}$ no etanol hidratado, esta é mais uma indicação que robustece as estimativas obtidas no modelo de formação do preço de etanol hidratado apresentado.

\section{Conclusão}

A política de combustíveis é uma das mais relevantes em praticamente todas as grandes economias mundiais. No caso brasileiro, as diretrizes estratégicas delineadas pelo governo local, ora estimulando o desenvolvimento de um mercado de combustível biorrenovável como o etanol, ora voltando-se ao desenvolvimento dos combustíveis fósseis tem dificultado o planejamento de longo-prazo, particularmente para um setor cuja principal matéria prima é agrícola e semiperene. O presente trabalho foi idealizado para analisar e apresentar evidências dos efeitos do controle de preço da gasolina adotado pelo governo brasileiro, o que só é possível por causa do monopólio de uma empresa estatal (Petrobrás) na oferta deste produto. Os resultados do presente trabalho sugerem que a regulamentação no mercado de combustível brasileiro, feito para manter os preços da gasolina relativamente constantes, têm ora afetado positivamente ora negativamente o consumo do biocombustível renovável.

Inicialmente, até 2010, o controle no preço da gasolina A no país parece ter tido como meta principal o incentivo ao biocombustível no país, tornando-o mais competitivo que o seu concorrente fóssil do que seria caso o preço internacional da gasolina fosse repassado ao 
mercado doméstico. Neste período, o baixo nível da taxa de câmbio (Reais por Dólar) foi um dos principais fatores com os quais o governo lutou para manter mais elevado o preço doméstico da gasolina. A seguir, até o ano de 2014, a interferência do governo brasileiro no mercado de combustíveis automotivos via controle do preço da gasolina A visou restringir os aumentos no preço internacional da gasolina, de maneira a impedir impactos negativos para a inflação no país. Entretanto, esta política prejudicou tanto os produtores de etanol, pois seus preços ficaram atrelados aos baixos níveis de preços da gasolina, quanto a empresa estatal responsável pela oferta doméstica da gasolina A no país (Petrobrás), que teve que arcar com a diferença entre o preço internacional e o definido domesticamente, e num período em que as importações de gasolina explodiram no país (as importações deste produto no período 2006-2010 foram cerca de 1\% das importações no período 2011-2015). Já a partir de 2015, frente às inúmeras críticas à política que desincentivou a produção de etanol combustível no país, com graves consequências econômicas e sociais, e também ao alto nível de endividamento da Petrobrás em função do controle do preço da gasolina $\mathrm{A}$, o governo mudou novamente seu foco. Ainda pelo controle do preço da gasolina A, mas agora a um nível mais elevado do que o observado no mercado internacional, o governo volta a estimular o biocombustível no país e, concomitantemente, melhorando as reservas financeiras da empresa responsável por este controle (Petrobrás). Entretanto, neste momento tem-se características bem distintas daquele entre 2006-2010. Enquanto naquele período o preço mais elevado vinha cobrindo os baixos níveis da taxa de câmbio no país, agora observa-se um período com alto valor do câmbio (taxa de câmbio no período 2006-2010 cerca de metade da observada em 2015), mas com o preço internacional da gasolina reduzindo e numa tendência clara de queda. Dessa maneira, este novo controle de preço vem cobrindo mais o preço internacional da gasolina e não a taxa de câmbio, como observado anteriormente. Este é um fator importante, uma vez que a política de controle deste preço joga contra também a competitividade nacional em outros setores, uma vez que os combustíveis fósseis são insumos básicos para a produção, e enquanto o mundo se beneficia desta redução mundial do preço deste insumo, o Brasil atua na contramão deste processo. 
Quanto à definição do processo de formação de preços do etanol hidratado como uma função do preço da gasolina, esta foi confirmada, tornando mais importante a avaliação dos efeitos da intervenção do governo no mercado do biocombustível. Por outro lado, esta influência deve ter uma elasticidade preço da gasolina para o etanol hidratado menor do que a unidade, o que foi observado no presente estudo. Entretanto, devido à baixa variação nos preços dos combustíveis no período analisado (ocorridas justamente em função do controle exercido pelo governo e analisado neste estudo) torna-se importante fazer uma ressalva quanto aos valores das elasticidades estimadas no presente trabalho. Qual seja, deve-se considerar que as variações no preço da gasolina superiores às observadas no período analisado podem gerar impactos diferentes nos preços do biocombustível. Portanto, a elasticidade estimada reflete as condições do período analisado, podendo ser utilizadas para fazer inferências para àquele período ou outros com características similares.

\section{Referências}

AGÊNCIANACIONAL DO PETRÓLEO-ANP (Brasil). Sistema de levantamento de preços. Disponível em: <http://www.anp.gov.br/preco/>. Acesso em: 05 de dez. 2016.

AS PERDAS da Petrobrás. Estado de São Paulo, São Paulo, 26 nov. 2012. Primeiro Caderno, p. 3.

AS USINAS estão parando. Estado de São Paulo, São Paulo, 25 fev. 2013. Primeiro Caderno, p. 3.

BACCHI, M.R.P. Formação de preços no setor sucroalcooleiro da região Centro-Sul do Brasil: relação com o mercado de combustível fóssil. In: ENCONTRO NACIONAL DE ECONOMIA, 33, 2005, Natal - RN. Anais. 2005.

BARROS, J.R.M. Etanol e carro flex: uma inovação que definha. Estado de São Paulo, São Paulo, 14 out. 2012. Caderno Economia \& Negócios, p. 7.

BEIRAL, P.R.S. O mercado brasileiro de etanol: concentração e poder de mercado sob a ótica da Nova Organização Industrial Empírica. Dissertação (Mestrado). Universidade de São Paulo, Piracicaba, SP, 2011.

BRASIL. Cide/Combustível: contribuição de intervenção no domínio econômico. Disponível em: $<$ http://www.receita.fazenda.gov.br/legislacao/legisassunto/cidecombustiveis.htm>. Acesso em: 20 de nov. 2016a.

BRASIL. Ministério da Agricultura, Pecuária e Abastecimento. Mistura Carburante Automotiva (etanol anidro / gasolina): cronologia. Disponível em: <http:/www.faespsenar.com.br/arquivos/pdf/gerais/ faesp/eco/Bioenergia-Legislacao/Percentual\%20de\%20Mistura-gasolina\%20(MAPA)-2011.pdf $>$. Acesso em: 20 de nov. 2016 b.

BRASIL. Ministério do Desenvolvimento, Indústria e Comércio Exterior. Comércio Exterior. Estatísticas de Comércio Exterior. Aliceweb. Disponível em: <http://aliceweb.desenvolvimento.gov.br $>$. Acesso em: 20 de nov. 2016c. 
BRASIL. Ministério do Planejamento, Orçamento e Gestão. Instituto Brasileiro de Geografia e Estatística. Economia. Contas Regionais. Disponível em: < http://www.ibge.gov.br/home/estatistica/ economia/contasregionais/2010/default.shtm>. Acesso em: 20 de nov. 2016d.

BRASILEIRO abastece mais com gasolina e afeta metas de mudanças climáticas. Estado de São Paulo, São Paulo, 05 mar. 2012. Primeiro Caderno, p. 12.

CARDOSO, L.C.B.; BITTENCOURT, M.V.L. Elasticidades da demanda de curto e longo prazo por etanol no Brasil no período de 2001 a 2011: um estudo utilizando painéis cointegrados. In: ENCONTRO NACIONAL DA SOBER, 10, 2012, Recife - PE. Anais, 2012.

CAROPREZO, J.S. Estimativa das elasticidades preço e renda da demanda por etanol nos Estados Unidos e no Brasil. Dissertação (Mestrado) - Ibmec, Rio de Janeiro, RJ, 2011.

CAVALCANTI, M.C.B. Tributação relativa etanol-gasolina no Brasil: competitividade dos combustíveis, arrecadação do estado e internalização de custos de carbono. Tese (Doutorado). Universidade Federal do Rio de Janeiro, Rio de Janeiro, RJ, 2011.

CERQUEIRA, M.N.P.S.; COSTA, C.C. Análise das políticas de formação do preço da gasolina C e impacto no mercado de etanol no Brasil. In: CONGRESSO DA SOBER, 49, 2011, Belo Horizonte, MG. Anais, 2011.

COM MUDANÇA contábil, Petrobrás eleva lucro e pode reforçar caixa do governo. Estado de São Paulo, São Paulo, 12 jul. 2013. Caderno Economia \& Negócio, p. 1.

COMBUSTÍVEIS para crise. Estado de São Paulo, São Paulo, 31 jan. 2013. Primeiro Caderno, p. 3.

COSTA, C.C.; BURNQUIST, H.L.; VALDES, C.; SOUZA, M.J.P. Modeling fuel demand in Brazil: the importance of the flex-fuel vehicle. Mimeo, 2014.

COSTA, C.C.; BURNQUIST, H.L.; VALDES, C.; SOUZA, M.J.P. Supply behavior or hydrous ethanol in Brazil. Economia Aplicada, v.19, n.4, dez. 2015.

COSTA, C.C.; GUILHOTO, J.J.M. O papel da tributação diferenciada dos combustíveis no desenvolvimento econômico do Estado de São Paulo. Economia Aplicada, v. 15, n.3, p. 371-392, 2011.

ERNST \& YOUNG TERCO. Brasil sustentável: perspectivas dos mercados de petróleo, etanol e gás. Disponível em: <http://fgvprojetos.fgv.br/sites/fgvprojetos.fgv.br/files/estudo_20.pdf>. Acesso em: 28 de mar. 2013. 2011.

FARINA, E. Conjuntura econômica e sustentabilidade. In: CONGRESSO DA SOBER, 51, 2013, Belém, PA. Anais, 2013.

FREITAS, L.C.; KANEKO, S. Ethanol demand in Brazil: Regional approach. Energy Policy, v. 39, n. 6, pp. 2289-2298, 2011.

FUNDAÇÃO GETÚLIO VARGAS-FGV. Pesquisa. Instituto Brasileiro de Economia. Indicadores de Preços. Disponível em: <http://portalibre.fgv.br/main.jsp?lumChannelId=402880811D8E34B90 11D92B6B6420E96>. Acesso em: 20 de nov. 2016.

GOLDEMBERG, J. Uma oportunidade histórica perdida? Estado de São Paulo, São Paulo, 18 mar. 2013. Primeiro Caderno, p. 2.

MENDONÇA, H.F. Metas para inflação e taxa de juros no Brasil: uma análise do efeito dos preços livres e administrados. Revista de Economia Política, São Paulo, v. 27, n. 3 (107), p. 431-451, 2007.

MING, C. Muito tarde e muito pouco. Estado de São Paulo, São Paulo, 31 jan. 2013. Caderno Economia \& Negócios, p. 2.

MING, C. O caixa da Petrobrás. Estado de São Paulo, São Paulo, 22 nov. 2012. Caderno Economia \& Negócios, p. 2.

NUNES, C.; GOMES, C. Aspectos concorrenciais do varejo de combustíveis no Brasil. In: SECRETARIA DE ESTADO DA FAZENDA. Regulamento do ICMS - RICMS. Disponível em: sites individuais para cada estado do Brasil. Acesso em: junho de 2013.

SERRANO, F. Juros, câmbio e o sistema de metas de inflação no Brasil. Revista de Economia Política, São Paulo, v. 30, n. 1, p. 63-72, 2010. 
SOUZA, A.N. Estudo das demandas de etanol e gasoline no Brasil no período 2001-2009. Dissertação (Mestrado) - Escola de Economia de São Paulo/Fundação Getúlio Vargas, São Paulo, 2010.

UNIÃO DA INDÚSTRIA DE CANA-DE-AÇÚCAR-UNICA Unicadata. Preços e cotações. Mapa de preços dos combustíveis. Disponível em: <http://www.unica.com.br>. Acesso em: 20 de nov. 2016.

UNITED NATIONS COMMODITY TRADE STATISTICS DATABASE-UNCTSD. COMTRADE. Disponível em: $<$ http://comtrade.un.org/db/>. Acesso em: 02 de nov. 2014.

UNIVERSIDADE DE SÃO PAULO-USP. Escola Superior de Agricultura Luiz de Queiroz. Centro de Estudos Avançados em Economia. CEPEA. Disponível em: <http://www.cepea.esalq.usp.br/>. Acesso em: 20 de nov. 2014. 